Bond University

Research Repository

\title{
Simplifying the cattellian psychometric model
}

\section{Boyle, Gregory J.}

\section{Published in:}

The SAGE Handbook of Personality Theory and Assessment: Volume 1 - Personality Theories and Models

DOI:

10.4135/9781849200462.n12

Licence:

Other

Link to output in Bond University research repository.

Recommended citation(APA):

Boyle, G. J. (2008). Simplifying the cattellian psychometric model. In G. J. Boyle, G. Matthews, \& D. H.

Saklosfke (Eds.), The SAGE Handbook of Personality Theory and Assessment: Volume 1 - Personality Theories and Models (pp. 257-272). SAGE Publications Ltd. https://doi.org/10.4135/9781849200462.n12

\section{General rights}

Copyright and moral rights for the publications made accessible in the public portal are retained by the authors and/or other copyright owners and it is a condition of accessing publications that users recognise and abide by the legal requirements associated with these rights.

For more information, or if you believe that this document breaches copyright, please contact the Bond University research repository coordinator. 


\section{Bond University}

\section{ePublications@bond}

Humanities \& Social Sciences papers

Faculty of Humanities and Social Sciences

$1-1-2008$

\section{Simplifying the Cattellian psychometric model}

Gregory J. Boyle

Bond University, Gregory_Boyle@bond.edu.au

Follow this and additional works at: http://epublications.bond.edu.au/hss_pubs

Part of the Personality and Social Contexts Commons

\section{Recommended Citation}

Boyle, Gregory J., "Simplifying the Cattellian psychometric model" (2008). Humanities \& Social Sciences papers. Paper 298.

http://epublications.bond.edu.au/hss_pubs/298

This Book Chapter is brought to you by the Faculty of Humanities and Social Sciences at ePublications@bond. It has been accepted for inclusion in Humanities \& Social Sciences papers by an authorized administrator of ePublications@bond. For more information, please contact Bond University's

Repository Coordinator. 
Word Count: 8,586

\title{
Simplifying the Cattellian Psychometric Model
}

\author{
Gregory J. Boyle \\ Department of Psychology, Bond University \\ and
}

Department of Psychiatry, University of Queensland

This chapter concerns the scientific analysis of individual differences in human psychological functioning including personality structure, undertaken by the author over a 30-year period (Boyle, 2006b). A key aspect of this programmatic work has been the taxonomic delineation of psychological constructs relating to cognitive abilities, personality traits (both normal and abnormal), dynamic (motivation) traits, and transitory (emotional/mood) states within the framework of the Cattellian Psychometric Model (e.g., see Cattell, 1973, 1979, 1980a,b, 1982a, 1983, 1984, 1988a,b,c, 1990a,b,c; 1995; Cattell \& Child, 1975; Cattell \& Horn, 1982; Cattell \& Kline, 1977; Cattell \& Nesselroade, 1984; Cattell et al., 2002). This extensive body of taxonomic psychometric research has been empirical and measurement oriented, using a combination of multivariate experimental and quasi-experimental designs (e.g., Boyle, 1988c; Boyle et al., 1995; Cattell, 1988b,c,e) although some critical reviews and integrative position papers have also been generated (e.g., Boyle, 1985b; Boyle \& Cattell, 1987; Boyle \& Smári, 2002; Boyle et al., 1999).

Raymond B. Cattell, PhD., DSc (London) was a prodigious, psychometrically-oriented behavioural scientist, listed among the top 10 most highly cited psychologists of the $20^{\text {th }}$ 
century (Haggbloom et al., 2002, p. 142). Cattell led a team of internationally visible researchers in undertaking a programmatic series of innovative psychometric research studies into the structure and assessment of human personality and individual differences (e.g., see Cattell, 1980a,b). The Cattellian School contributed significantly to the contemporary understanding of human personality constructs, and made numerous psychometric advances, including several technical refinements to exploratory factoranalytic methodology as well as being responsible for the construction of a wide range of factor-analytically derived measurement instruments. Cattell was the recipient of several prestigious awards and prizes, including for example, the Wenner Gren Prize of the New York Academy of Sciences, Distinguished Honorary membership of the British Psychological Society, the Darwin Fellowship, and inaugural president of the Society of Multivariate Experimental Psychology (SMEP), which he founded (see Cattell, 1990b). Cattell also was involved in founding the Institute for Personality and Ability Testing (IPAT) which is recognized internationally as a major publisher of a wide range of factoranalytically based psychological tests and measurement instruments.

Nevertheless, the report by Haggbloom et al. (2002) confirms that even though both Cattell and Eysenck were listed as among the 10 most highly cited psychologists in the published journal literature (attesting to their vast empirical outputs), the number of citations of their work in general psychology textbooks and in a survey of American Psychological Society (now Association for Psychological Science) members was disproportionately lower. In Cattell's case, part of the difficulty may reside in the complex mathematical models underpinning the Cattellian Psychometric Model, thereby making his writings difficult to comprehend. Moreover, the Cattellian Psychometric Model was unnecessarily complicated, including no fewer than 92 primary factors--far too many for practical utility. 
Simplifying the overly large taxonomy of Cattellian psychological constructs was demonstrably needed. Accordingly, a sustained, programmatic sequence of exploratory and confirmatory factor-analytic studies was conducted over several years with the goal of elucidating a reduced number of broad factors that would have greater utility for psychological measurement, test construction and professional practice. Other multivariate statistical procedures such as canonical correlation analysis, multiple regression analysis, discriminant function analysis, multidimensional scaling, multivariate analysis of variance, and structural equation modelling were employed, as required (cf. Boyle, 1983b, 1991a; Nesselroade \& Cattell, 1988). As a result of this programmatic research, the 92 primary Cattellian Psychometric Model factors were reduced down to just 29 broad factors (a 68\% reduction) - i.e., 30 broad factors with addition of the separate factor-analytically elucidated curiosity construct (see Boyle, 1983b, 1989a). The resultant Boyle Psychometric Model, is not only more concise, but also retains the specificity needed for detailed measurement across several psychological domains including both the normal and abnormal personality spheres (cf. Boyle et al., 2001; Boyle \& Smári, 2002).

Thus, a major reduction in number of taxonomic psychological constructs has been achieved through the systematic factor analysis of the primary factor intercorrelations measured in the Cattellian psychometric instruments (see descriptions of instruments in Cattell, 1973, 1988d; Cattell \& Schuerger, 1978; Cattell \& Johnson, 1986; Curran \& Cattell, 1976; Krug, 1980; Schuerger, 1986; Smith, 1988; Sweney et al., 1986). In regard to exploratory factor analytic methodology (see Cattell, 1978; Gorsuch, 1983), an empirical study (Boyle \& Stanley, 1986) demonstrated that the simple structure of factor-pattern solutions (cf. Child, 1990) can be maximised by applying a topological rotation in addition to analytical rotation alone (e.g., via the Statistical Package for the Social Sciences, SPSS). 
Nevertheless, the actual increase in simple structure (measured via the \pm 0.10 hyperplane count—see Cattell, 1978) was only about 6\%, making it hard to justify all the extra effort required. On the other hand, a critical review of factor-analytic methodology (Boyle, 1993b) appears to have preceded new enhancements being incorporated into the SPSS exploratory factor-analytic programs (e.g., inclusion of the psychometric Scree test—see Cattell, 1988d), increasing the efficiency and practical utility of the current SPSS factoranalytic programs.

In these studies (see Boyle, 2006b), the specific factor-analytic methodology used, mostly employed either an iterative maximum-likelihood or a principal-factoring procedure, together with factor extraction number estimated via careful application of the psychometric Scree test (Cattell, 1978, 1988d). In several empirical investigations (e.g., Cattell \& Vogelmann, 1977; Hakstian et al., 1982), the psychometric Scree test had been shown to be considerably more accurate than Kaiser's eigenvalues greater than 1.0 rule (which underestimated the number of factors when there were fewer than about 20 variables, and seriously overestimated the number of factors when there were more than about 40 variables in the analysis). In addition, oblique rotation (either direct Oblimin or Promax) was employed throughout, in the search for maximum simple-structure factor solutions, as indexed via the \pm .10 hyperplane count (cf. Boyle, 1993b; Cattell, 1978, 1988d; Child, 1990;; McArdle, 1984; McArdle \& Cattell, 1994). In future work, it is planned to construct a comprehensive set of modern neo-Cattellian psychometric instruments based on the reduced set of broad factors that now has been elucidated. Specifically, the focus will be on the construction of (T-data) objective test measures, thereby avoiding the serious drawback of item-transparent, self-report (subjective) questionnaires, currently so prevalent within the personality assessment field (cf. Boyle, 1985b; Cattell, 1979, p. 123; Schuerger, 
1986; Smith, 1988). Accordingly, this chapter not only summarizes an extensive body of past empirical research efforts, but also provides the point of departure for significant future works, based on improved psychometric test construction principles.

A concise taxonomy of psychological constructs (akin to the periodic table in chemistry) is yet to be formulated. Within the framework of the general psychometric model (Kline, 1979, 1980), the initial task is the empirical (factor-analytic) delineation of psychological constructs including cognitive/intellectual abilities, relatively stable personality traits (both normal and abnormal), less stable dynamic (motivational) traits, and transitory, situationally-sensitive mood states. In line with the dictum that measurement is the sine qua non of any scientific enterprise, so too, psychological science depends on valid and reliable psychometric instruments that measure inferred psychological (including personality) constructs. Aside from the empirical elucidation and quantitative measurement of psychological constructs, per se, psychological science also involves differential empirical studies, and hypothesis testing experimentation (e.g., via functional psychological testing (Cattell, 1986d,e; Cattell \& Johnson, 1986; see Boyle, 1989g for a review). In line with Cronbach’s (1957) historic call for combining the "two disciplines" of scientific psychology, the published research collated in this chapter has attempted to meld both correlational and experimental approaches within the context of the Cattellian framework (cf. Eysenck, 1997), adopting wherever possible, a distinctly multivariateexperimental perspective (Boyle, 1988c, 1991b).

Use of exploratory factor-analytic procedures in the construction of personality instruments has produced somewhat conflicting outcomes. Thus, Eysenck reported three higher-stratum personality dimensions, as measured, for example, in the Eysenck Personality Questionnaire 
Revised or EPQ-R that were labelled Extraversion, Neuroticism, and Psychoticism (e.g., see Eysenck \& Eysenck, 1985), whereas Cattell reported 16 normal personality trait factors (BirkettCattell, 1989; Krug, 1981; see Boyle, 1990, for a review of the Sixteen Personality Factor Questionnaire (16PF) and Clinical Analysis Questionnaire (CAQ) personality trait instruments). Despite being rather unwieldy, the Cattellian Psychometric Model has enabled comprehensive measurement of cognitive abilities alongside normal and abnormal personality traits, dynamic (motivational) traits, and situationally-sensitive mood states (cf. Cattell, 1982b, 1988a; Eysenck, 1984). Thus, a key research focus has been the discovery, through use of exploratory factoranalytic methods, of a reduced set of higher-stratum factors within the Cattellian framework (Boyle, 2006b). In these studies, many non-Cattellian psychometric instruments have also been utilized both specifically and generically, not only for the purpose of validating or verifying their factor structure, but more importantly, to enable comparisons with instruments constructed within the framework of the Cattellian Psychometric Model, and in relation to the more concise, simplified Boyle Psychometric Model, subsequently elucidated.

Source traits delineated factor-analytically have been incorporated by the Institute for Personality and Ability Testing (IPAT) into several multidimensional measurement instruments including:

- $\quad$ Sixteen Personality Factor Questionnaire (16PF)

- $\quad$ Clinical Analysis Questionnaire (CAQ)

- $\quad$ Motivation Analysis Test (MAT)

- $\quad$ School Motivation Analysis Test (SMAT)

- $\quad$ Children's Motivation Analysis Test (CMAT)

- $\quad$ Eight State Questionnaire (8SQ)

- $\quad$ Objective-Analytic (O-A) Battery 


\section{- $\quad$ Culture Fair Intelligence Tests (CFIT) \\ - $\quad$ Comprehensive Ability Battery (CAB).}

Despite Cattell's enormous productivity, the complexity of his "all-inclusive” psychometric approach has tended to be rather problematic, serving as an ongoing source of frustration for many psychological researchers and practitioners alike. Indeed, as stated above, Cattell had elucidated no fewer than 92 primary factors, including 20 cognitive ability factors, 16 normal personality trait dimensions (including 16PF Factor B, Intelligence), 12 abnormal personality traits, 20 integrated/unintegrated dynamic traits, 12 normal mood states; and 12 abnormal mood states (derived from dR-factor analyses of Clinical Analysis Questionnaire subscale intercorrelations), which was too unwieldy for practical utility. It was evident that a reduction in number of taxonomic constructs was urgently needed (Kline, 1979, 1980), and the Cattellian Psychometric Model with its emphasis on numerous primary factors, provided a logical starting point for elucidating a reduced set of pertinent higher-stratum constructs. In contrast, the Eysenckian Psychometric Model (EPM) was too minimalist, accounting for only a small fraction of the known personality trait variance (cf. Boyle et al., 1995; Cattell, 1986g, 1995). Thus, the Eysenkian factors provided an inadequate account of the dimensionality of abnormal personality structure (i.e., the unitary Psychoticism scale is problematic in light of the several varieties and subtypes of psychopathology documented in the DSM-IV-TR or ICD-10 psychodiagnostic classification manuals, respectively). Additional goals (Boyle, 2006b) also included the clarification and refinement of methodological issues relating to exploratory factor analysis, as well as undertaking empirical studies into personality within various applied settings. 
Several of the studies presented in this chapter were published either in Multivariate Experimental Clinical Research or in Personality and Individual Differences, in order to disseminate the research findings to the comparatively small, but select target audience interested in multivariate psychometric research related to personality and individual differences within the Cattellian framework. In contrast to more subjective test construction approaches, the empirical use of factor analysis was used to map out the important underlying psychological constructs, and the derived factors guided subsequent construction of measurement instruments (e.g., Boyle, 1992, 1999). Importantly, since each of the Cattellian instruments including the Sixteen Personality Factor Questionnaire or 16PF (Cattell et al., 1970; Krug, 1981), the Motivation Analysis Test or MAT (Cattell, 1985; Cattell \& Child, 1975; Sweney et al., 1986), and the Eight State Questionnaire or 8SQ (Curran \& Cattell, 1976) measured essentially discrete variance (see Boyle et al., 1985), and in light of relevant psychometric principles (Boyle, 1985b), the search for higher-stratum factors within each intrapersonal psychological domain appeared especially promising. Accordingly, the sustained program of multivariate research studies presented here comprised many factor analyses of empirical data derived mostly from large samples that cumulatively involved psychometric assessment of many thousands of individuals.

Boyle (1989f) and Fisher and Boyle (1997) reported the higher-stratum factor structure of normal personality traits measured in the Sixteen Personality Factor Questionnaire (cf. Cattell, 1994, 1995; Cattell \& Krug, 1986; Krug \& Johns, 1986), thereby providing support for a simplified and more practical structure of five broad personality dimensions (a 69\% reduction). In a factor analysis of the subscale intercorrelations of the 16PF/MAT/8SQ instruments (the first ever such combined study), Boyle (1988c) also reported three additional normal personality dimensions, thereby enabling measurement of a substantially 
greater proportion of the personality trait variance than that provided by the Eysenkian factors. Previously published data for the 16PF, the Comrey Personality Scales; and the Eysenck Personality Inventory (an early version of the Eysenck Personality Questionnaire or EPQ) was subjected to close scrutiny (Boyle (1989f) using methodologically sound factor-analytic procedures (see Boyle, 1985b, 1988c, 1993b; Boyle \& Stanley, 1986; and Boyle et al., 1995, for specification of the factor-analytic methodology employed). Results of this well-cited reanalysis confirmed the work of Krug and Johns (1986) that there are at least five broad normal personality factors labelled: Extraversion, Anxiety-Neuroticism, Tough Poise, Independence, and Control. These five second-stratum factors have made a substantial impact, having been incorporated, for example, into the revised Sixteen Personality Factor Questionnaire (5 ${ }^{\text {th }}$ edition or 16PF5; see H.E.P. Cattell, 2001, 2004; R.B. Cattell \& H.E.P. Cattell, 1995; Cattell \& Schuerger, 2003). These higher-stratum 16PF5 factors were shown to compare more than favourably with other models of personality structure such as the currently popular Five Factor Model (FFM)—(see Boyle, 2006a; Fisher \& Boyle, 1997), and were found to correspond with primary T-data factors measured in the Objective-Analytic Battery (OAB)--(Cattell \& Birkett, 1980).

Boyle et al. (1995) in their chapter in the International Handbook of Personality and Intelligence provided a detailed technical critique of the exploratory factor-analytic research leading to development of both the Sixteen Personality Factor Questionnaire and the currently popular Five Factor Model (cf. Boyle, 2006a; H.E.P. Cattell, 1993). Importantly, simple structure for the Sixteen Personality Factor Questionnaire secondstratum factor solution (measured via the \pm 0.10 hyperplane count-see Cattell, 1978) was significantly greater than that observed for the Five Factor Model (Boyle et al., 1995; Boyle \& Smári, 1997, 1998, 2002; Boyle \& Saklofske, 2004; Krug \& Johns, 1986), 
suggesting that the Sixteen Personality Factor Questionnaire second-stratum factors provide a more satisfactory structuring of the normal personality trait domain than does the popular Five Factor Model. However, since the second-stratum Factor QIII (Tough Poise), calculated via the algorithm provided in the 16PF Handbook produced spurious results, Boyle and Robertson (1989) recommended that previous studies involving the computation of second-stratum Sixteen Personality Factor Questionnaire factors should be reanalysed in light of the new corrected algorithm. Since historically, the Sixteen Personality Factor Questionnaire has been the most highly cited psychometric measure of normal personality, the potential impact of correcting this computational error was considerable.

Parenthetically, we had demonstrated (Cattell et al., 2002) that personality traits are susceptible to modification as a function of life experience, indicative of substantial “structural learning” (see Cattell, 1983; Cattell et al., 2002; Roberts et al., 2006a,b). This finding casts doubt on the adequacy of "static" models of personality structure such as the Five Factor Model, thereby providing an advance in our understanding of the structuring of human personality. This new knowledge that personality traits are not fixed, immutable dispositions, but rather are only relatively stable dispositions that are subject to structural change (e.g., as a result of learning and enculturation) undoubtedly will impact greatly on the future construction of personality measurement instruments.

Boyle (1987b) also reported a number of second-stratum factors within the abnormal personality trait domain. The 12 abnormal (psychopathological) trait dimensions measured in the Clinical Analysis Questionnaire or CAQ (Krug, 1980) were reduced down to just six second-stratum factors (a 50\% reduction) that were labelled: Depressive Schizophrenia, Psychopathic Dominance, Psychotic Inadequacy, Paranoid Depression, Helpless 
Depression, and Anxious Depression, thereby providing a much greater economy of measurement. Furthermore, the seven primary Clinical Analysis Questionnaire depression factors were reduced down to just four broad depression factors, having greater practical, conceptual and measurement utility for researchers and professional psychologists alike (cf. Boyle \& Comer, 1990). It is to be hoped that the impact of these findings will likely be realised with future construction of more efficient measures of abnormal personality, based on broad second-stratum, rather than focusing on a plethora of narrow primary trait factors.

Turning to the dynamic (motivation) trait domain (e.g., see Barton et al., 1986; Cattell, 1981, 1985; 1992; Cattell \& Child, 1975; Cattell \& Kline, 1977; Kline, 1979) several publications (e.g., Boyle, 1985a, 1988c, 1989b; Boyle \& Start, 1988, 1989a; and Boyle et al., 1989a) examined the higher-stratum factor structure of objective motivation tests (Tdata measures avoid the problematic item transparency and associated response distortion that plagues Q-data self-report personality questionnaires). While objective tests of cognitive abilities have been used for decades, the use of objective motivation tests has been less prominent. A notable exception has been the Cattellian work with its incorporation of objective T-data tests into the Motivation Analysis Test (MAT) and its downward extensions, the School Motivation Analysis Test (SMAT) and Children's Motivation Analysis Test (CMAT), respectively (Boyle et al., 1988; Cattell, 1985, 1992; Cattell \& Child, 1975; Cattell \& Warburton, 1967).

Some early work (e.g., Boyle \& Cattell, 1984) had examined Motivation Analysis Test construct and predictive validity. It was found that presentation of a stressful stimulus induced significant elevations in several dynamic traits (especially Fear), lending confidence that factor-analytic refinements would be efficacious (parenthetically, the 
empirical findings obtained by Boyle and Cattell also suggested that fear appeals, in the absence of positive instructions, are likely to be ineffective in promoting safer driving behaviours). An earlier factor analysis of the subscale intercorrelations of the MAT/8SQ instruments was subsequently revised (Boyle, 1985a) using more methodologically sound factor-analytic procedures, resulting in reduction of the 20 integrated/conscious (I) and unintegrated/unconscious (U) primary Motivation Analysis Test dimensions down to just seven second-stratum factors (a 65\% reduction). The broad dynamic trait factors delineated were labelled: Home Orientation, Pugnacity, Narcism (narcissism), Career Orientation, Fear, Self-sentiment, and Superego (specific factor-analytic procedures were provided in Boyle, 1993b). Accordingly, an updated, simplified Motivation Analysis Test, constructed to measure the above higher-stratum factors, would make the instrument more useful as a measure of dynamic traits. The impact of such a revised addition to the psychometric armamentarium would likely be considerable, since objective T-data tests of motivation are rare.

Boyle (1989b) also investigated higher-stratum factors in the School Motivation Analysis Test (version used with adolescents). The 20 (U and I) primary factors were reduced down to just five second-stratum factors (a 75\% reduction). In line with the recent verification that personality structure can be modified somewhat as a result of experience (Cattell et al., 2002), so too, reduction in second-stratum factors (five SMAT factors versus seven MAT factors) pointed to the developmental nature of motivational structure. In Boyle et al. (1989a), evidence for a possible sixth second-stratum School Motivation Analysis Test factor was obtained. However, variation in factor pattern solutions suggested that, as with the objective Motivation Analysis Test, further psychometric refinement of the School Motivation Analysis Test was also required (cf. Boyle et al., 1989a,b). Hopefully, such a 
revised objective T-data instrument would enable the valid measurement of factoranalytically elucidated dynamic traits among adolescents.

In addition, Boyle and Start (1988) reported broad second-stratum Children's Motivation Analysis Test factors (version used with primary school children). The four factors that emerged (an 80\% reduction) were labelled: Superego, Narcism (narcissism), Play, and Selfsentiment. It was noted that School Orientation (second-stratum SMAT factor) was not included among the Children's Motivation Analysis Test second-stratum factors, suggesting perhaps that primary school children have not yet developed a strong motivational focus on school activities (cf. Boyle \& Houndoulesi, 1993). This finding is consistent with the observation that motivational structure itself is partly a product of experiential learning, wherein sentiments are culturally acquired. In a comparison of gender differences in motivation (Boyle \& Start, 1989a,b), the second-stratum factor loadings for primary school boys and girls differed appreciably, suggesting general differences in interests and motivational structure. Girls obtained significantly higher mean scores on Fear, Pugnacity, and Curiosity, whereas boys obtained significantly higher scores on Play. Theoretically, at least, if these observed gender differences in motivation were taken into account and explicitly capitalised upon with the aim of producing enhanced educational outcomes, the impact of this finding could be considerable.

A research note (Boyle (1989c) reported the first available normative data for the (unpublished) Children's Motivation Analysis Test. Provision of this normative data was useful, establishing an objective basis for comparing children's Children's Motivation Analysis Test scores. In a study that manipulated curiosity and boredom states, Boyle et al. (1993) provided some predictive validity for the instrument. Four of the 20 (U and I) 
CMAT factors exhibited significant changes in mean scores following experimental interventions (decreases were observed in I-Assertiveness and I-Fear; increases were observed in U-Narcism and U-Pugnacity). These findings (cf. Boyle \& Cattell, 1984) provided further evidence of the situational sensitivity of the dynamic trait factors. It was observed also that Superego and Self-sentiment appeared to emerge factor analytically as "master sentiments" for all three MAT/SMAT/CMAT instruments. Finally, Boyle (1988c)--in the Handbook of Multivariate Experimental Psychology--summarized the psychometric findings from several empirical studies carried out conjointly into the MAT/SMAT/CMAT instruments. While some evidence of predictive or discriminative validity was observed in each case, it was also apparent that these instruments need extensive psychometric revision, not only to simplify their factor structure, but also to bring them up-to-date for contemporary use.

Turning to the mood-state domain, both canonical correlation analyses and multiple regression analyses, as well as several exploratory factor analyses were undertaken in an attempt to quantify the measurement overlap (in terms of percentage of common measurement variance) across the 8SQ/DES-IV instruments (Boyle, 1986, 1989d). Results demonstrated that only a small number of the Differential Emotions Scale (DES-IV) subscales predicted most of the 8SQ variance, and vice versa, showing that the Eight State Questionnaire (8SQ) alone does not provide comprehensive assessment of the mood-state domain. Redundancy analyses of the 8SQ/POMS instruments (cf. Boyle, 1987b) demonstrated that the Eight State Questionnaire and Profile of Mood States (POMS) instruments measured considerable discrete variance, supporting the search for higherstratum state factors from factor analyses of all three 8SQ/POMS/DES-IV mood-state instruments. 
Accordingly, several factor-analytic studies (Boyle, 1987d, 1988a, 1989e, 1991c) sought higher-stratum mood state factors from the 8SQ/POMS/DES-IV instruments (while Cattell had delineated 12 mood-state factors, only the first eight were incorporated into the 8SQ). The outcome of these studies was a significant reduction from 12 primary factors down to just four broad mood-state factors (a 67\% reduction) that were labelled: State Extraversion, State Neuroticism, State Hostility, and Arousal-Fatigue, respectively. In addition, a differential (dR) scale factoring of the Clinical Analysis Questionnaire (Boyle, 1987a) provided evidence for two abnormal mood-state factors (an 83\% reduction) that were labelled Paranoid State and Psychopathic Dominance State, respectively (cf. Cattell \& Kameoka, 1985). Taken together, these findings provided justification for the construction of new simplified scales that focused on broad second-stratum dimensions. In Boyle and Katz (1991), multidimensional scaling (MDS) of 8SQ/DES-IV data also revealed that most DES-IV subscales were aligned in close proximity to each other, suggesting inadequate separation, and therefore suggesting the need for psychometric refinement of the Differential Emotions Scale. In contrast, separate factor analyses of the POMS/8SQ (see Boyle, 1988a) confirmed the purported factor structure for each instrument.

In regard to the taxonomic structure of cognitive abilities, a hierarchical model comprising broad higher-stratum factors, several primary factors, and numerous specific abilities also had been postulated within the Cattellian Psychometric Model (e.g., Cattell, 1982a, 1987a; Cattell \& Cattell, 1977). Boyle (1988b, 1995) reported that both Fluid $\left(\mathrm{G}_{\mathrm{f}}\right)$ and Crystallised $\left(\mathrm{G}_{\mathrm{c}}\right)$ intelligence factors are accompanied by a number of important secondstratum ability factors labelled: Memory Capacity $\left(\mathrm{G}_{\mathrm{m}}\right)$, Perceptual Speed $\left(\mathrm{G}_{\mathrm{ps}}\right)$, Retrieval Capacity $\left(\mathrm{G}_{\mathrm{r}}\right)$, Visualisation Capacity $\left(\mathrm{G}_{\mathrm{v}}\right)$, and Auditory Organisation $\left(\mathrm{G}_{\mathrm{a}}\right)$. This 
reduced number of ability factors, as compared with say the 20 primary factors measured in the Cognitive Ability Battery (CAB), would appear to have greater practical utility (a 75\% reduction). While these higher-stratum cognitive ability factors have been incorporated to some extent into existing ability measures there appears to be room for construction of a new, simplified intelligence test that simultaneously measures each of the higher-stratum factors and builds on well-established instruments such as the Stanford-Binet Intelligence Scale (SB-IV) and the Wechsler Intelligence Scales. Boyle (1990b) and Bernard et al. (1990) reported exploratory, congeneric and confirmatory factor analyses of SB-IV data that supported the four putative Area dimensions (Verbal Reasoning, Quantitative Reasoning, Abstract-Visual Reasoning, and Short-Term Memory). Boyle (1993a, 1995) as well as Boyle et al. (1995) and Stankov et al. (1995) examined the covariation between personality and cognitive ability measures. Their findings revealed only slight measurement overlap, suggesting that personality and ability factors measure essentially discrete psychological domains.

Other psychometric studies, either arising from or benefiting research into the Cattellian Psychometric Model, contributed new insights relating to: (1) use of change scores in canonical-redundancy analyses of multidimensional mood-state instruments, thereby avoiding "trait contamination variance" (Boyle, 1987e). This study demonstrated that neither the Eight State Questionnaire nor the Differential Emotions Scale provided comprehensive coverage of the mood-state domain, highlighting the need to include additional scales in factor analyses of mood-state data. (2) desirable levels of item homogeneity in psychometric scales (Boyle, 1991a). This highly cited study demonstrated that to achieve greater breadth of measurement, item homogeneity (e.g., as measured via the Cronbach alpha coefficient) should be moderate rather than maximal. (3) validity of 
meta-analytic procedures (Fernandez \& Boyle, 1996). This paper highlighted the importance of framing hypotheses in a rigorous operational manner, making adjustments and taking sample size into account in estimating effect sizes. (4) test validity as a function of method of administration (Grossarth-Maticek et al., 1995). This study demonstrated that the outcomes of psychological investigations may depend greatly on the particular test administration method employed. Taken together, these and other methodological papers have clarified several important psychometric issues, serving as an essential prerequisite for improved psychological test construction. In addition, substantive advances have included calculation of measurement redundancy across different instruments via canonical correlation analyses (e.g., 16PF/MAT); derivation of multiple regression prediction equations for translating scores across different measures (e.g., 8SQ/POMS/DES-IV); as well as elucidation of higher-stratum factors for both normal and abnormal (psychopathological) personality traits (16PF/CAQ), dynamic (motivation) traits (MAT/SMAT/CMAT), and transitory mood states (8SQ), respectively.

This sustained research program has also culminated in a number of integrative technical reviews and position papers (e.g., Boyle \& Smári, 2002; Boyle et al., 2001; Fisher \& Boyle, 1997) some of which were published in foreign-language peer-reviewed journals (Norwegian, Spanish, French, plus some abstracts in German and Japanese), thereby increasing international visibility and dissemination of the findings. Finally, Boyle and Saklofske (2004) provided a comprehensive and relatively up-to-date integrative overview of research findings within the field of personality and individual differences.

\section{Summary of Major Outcomes of this Research:}


- Justification of the search for higher-stratum factors, since 16PF/MAT/8SQ measured substantial discrete variance.

- $\quad$ Reduction of 16PF primary factors down to five broad factors. (69\% reduction)

- Demonstration of significantly greater simple structure for the 16PF second-stratum factors than for the FFM.

- $\quad$ Reduction of 12 CAQ abnormal personality trait dimensions down to six broad factors. (50\% reduction)

- $\quad$ Reduction of 20 (U and I) MAT factors down to seven broad factors. (65\% reduction)

- $\quad$ Reduction of 20 (U and I) SMAT factors down to five broad factors. (75\% reduction)

- $\quad$ Reduction of 20 (U and I) CMAT factors down to just four broad factors. ( $80 \%$ reduction)

- Demonstration that Superego and Self-sentiment emerged as "master sentiments" for all three MAT/SMAT/CMAT instruments.

- $\quad$ Reduction of 12 (8SQ/POMS/DES-IV) primary mood-state factors down to just four broad factors. (67\% reduction)

- $\quad$ Elucidation of two abnormal CAQ mood-state dimensions. (83\% reduction)

- $\quad$ Reporting of five broad ability factors. (75\% reduction)

- $\quad$ Reduction of 92 Cattellian Psychometric Model primary factors (ability, personality, motivation, and mood-state domains) down to 29 broad factors. (68\% reduction)

- $\quad$ Production of simplified Boyle Psychometric Model (30 broad factors with inclusion of the curiosity construct). 


\section{Methodological Recommendations}

- Evaluate item homogeneity in terms of both internal consistency and item redundancy and to enhance breadth of measurement by including greater diversity of items in psychometric scales.

- $\quad$ Use objective personality tests rather than subjective, item-transparent self-report scales (to avoid motivational/response distortion).

- $\quad$ Measure reliability via immediate and longer-term test-retest (dependability vs. stability) estimates for state-trait measures.

- $\quad$ Use methodologically sound exploratory factor-analytic (EFA) methods.

- $\quad$ Demonstrated that method of test administration significantly influences predictive validity of psychometric tests.

\section{Summary and Conclusions}

This sustained body of empirical research (Boyle, 2006b) has pinpointed a number of limitations in the psychometric assessment of personality and individual differences within the framework of the Cattellian Psychometric Model. It has identified several important questions needing to be addressed, and has included many experimental and/or empirical studies, providing a set of more practical taxonomic constructs for effective use by the psychological, medical, educational and commercial communities. The extensive body of taxonomic research provides a practical solution to the extreme/conflicting positions adopted by earlier investigators (e.g., Cattell’s comprehensive approach versus Eysenck's minimalist approach). Over many years, through the sustained application of factor analysis, a simplified version of the Cattellian Psychometric Model has been produced, resulting in a 68\% reduction from 92 factors down to 29 broad factors. With inclusion of the State Curiosity dimension (also elucidated factor analytically), the Boyle Psychometric 
Model, comprises 30 broad factors that, taken together, cover the intrapersonal psychological domains of cognitive abilities, personality traits, dynamic traits, and transitory mood states, respectively (see Table 1).

Put Table 1 about here

The next sequential step will be to construct a wide range of modern neo-Cattellian multidimensional psychometric instruments, incorporating the reduced number of higherstratum factors into objective test measures (rather than relying on item-transparent questionnaires with their inherently flawed self-report methodology). The plethora of socalled "personality tests" has literally exploded in recent years. Many of these are relatively simple rating scales (ratings of others or L-data; self ratings or Q-data). Aside from response sets, and superficial reporting, a major problem with subjective L-data and Q-data rating scales of personality/motivation is that they depend upon transparent, face valid items. Item transparency is extremely problematic, inviting response/motivational distortion, such that virtually all current "personality testing” is essentially based on subjective methodology. Correction scales can go only so far, and in some cases (e.g., the Minnesota Multiphasic Personality Inventory or MMPI K-scale) application of the proposed modification may produce "corrected" scores that are no more accurate than the “uncorrected” ones.

What is needed are truly objective interactive tests of personality traits (with computer implementation, and stimulus items individualised for each respondent). Indeed, Cattell 
and Warburton (1967) had produced a compendium comprising more than 2000 objective T-data personality tests, several of which were subsequently incorporated into the Objective Analytic Battery (Cattell \& Schuerger, 1978). Evidently, the field of personality measurement needs to be transformed out of its present quagmire (based predominantly on subjective self-report methodology) and lifted onto an altogether more technologically advanced level of objective-interactive testing (Schuerger, 1986).

Hopefully, neo-Cattellian instruments constructed to measure the higher-stratum factors delineated in the Boyle Psychometric Model should take approximately 70\% less time to administer than is currently required for all 92 Cattellian Psychometric Model primary factors using the currently available spectrum of Cattellian instruments (Boyle, 2006b). Such a major saving in testing time should have a considerable beneficial impact for various areas of psychological research and professional practice. Thus, the work presented in this chapter is more than just a summary of past research efforts. It also provides a rich source of hypotheses, and lays the very foundations for challenging and rewarding future works and directions in personality test construction. 


\section{References}

Barton, K., Dielman T. E., \& Cattell, R. B. (1986). Prediction of objective child motivation test scores from parents' reports of child-rearing practices. Psychological Reports, 59, 343-352.

Bernard, M. E., Boyle, G. J., \& Jackling, B. F. (1990). Sex-role identity and mental ability. Personality and Individual Differences, 11, 213-217.

Birkett-Cattell, H. (1989). The 16PF: Personality in depth. Champaign, IL: Institute for Personality and Ability Testing.

Boyle, G. J. (1983a). Critical review of state-trait curiosity test development. Motivation and Emotion, 7, 377-397.

Boyle, G. J. (1983b). Effects on academic learning of manipulating emotional states and motivational dynamics. British Journal of Educational Psychology, 53, 347-357.

Boyle, G. J. (1985a). A reanalysis of the higher-order factor structure of the Motivation Analysis Test and the Eight State Questionnaire. Personality and Individual Differences, 6, 367-374.

Boyle, G. J. (1985b). Self-report measures of depression: Some psychometric considerations. British Journal of Clinical Psychology, 24, 45-59.

Boyle, G. J. (1986). Estimation of measurement redundancy across the Eight State Questionnaire and the Differential Emotions Scale. New Zealand Journal of Psychology, 15, 54-61.

Boyle, G. J. (1987a). Psychopathological depression superfactors in the Clinical Analysis Questionnaire. Personality and Individual Differences, 8, 609-614.

Boyle, G. J. (1987b). Quantitative and qualitative intersections between the Eight State Questionnaire and the Profile of Mood States. Educational and Psychological Measurement, 47, 437-443. 
Boyle, G. J. (1987c). The role of intrapersonal psychological variables in academic school learning. Journal of School Psychology, 25, 389-392.

Boyle, G. J. (1987d). Typological mood-state factors measured in the Eight State Questionnaire. Personality and Individual Differences, 8, 137-140.

Boyle, G. J. (1987e). Use of change scores in redundancy analyses of multivariate psychological inventories. Personality and Individual Differences, 8, 845-854.

Boyle, G. J. (1988a). Central clinical states: An examination of the Profile of Mood States and the Eight State Questionnaire. Journal of Psychopathology and Behavioral Assessment, 10, 205-215.

Boyle, G. J. (1988b). Contribution of Cattellian psychometrics to the elucidation of human intellectual structure. Multivariate Experimental Clinical Research, 8, 267-273.

Boyle, G. J. (1988c). Elucidation of motivation structure by dynamic calculus. In J. R. Nesselroade \& R. B. Cattell (Eds.), $\underline{\text { Handbook of multivariate experimental }}$ psychology (2nd ed.) (pp. 737-787). New York: Plenum.

Boyle, G. J. (1989a). Breadth-depth or state-trait curiosity? A factor analysis of state-trait curiosity and state anxiety scales. Personality and Individual Differences, 10, 175183.

Boyle, G. J. (1989b). Central dynamic traits measured in the School Motivation Analysis Test. Multivariate Experimental Clinical Research, 9, 11-26.

Boyle, G. J. (1989c). Children's Motivation Analysis Test (CMAT): Normative data. Psychological Reports, 65, 920-922.

Boyle, G. J. (1989d). Factor structure of the Differential Emotions Scale and the Eight State Questionnaire revisited. Irish Journal of Psychology, 10, 56-66. 
Boyle, G. J. (1989e). Re-examination of the major personality-type factors in the Cattell, Comrey and Eysenck scales: Were the factor solutions by Noller et al. optimal? Personality and Individual Differences, 10, 1289-1299.

Boyle, G. J. (1989f). Review of R. B. Cattell \& R. C. Johnson's (1986) "Functional psychological testing: Principles and instruments." Multivariate Experimental Clinical Research, 9, 41-43.

Boyle, G. J. (1989g). Sex differences in reported mood states. Personality and Individual Differences, 10, 1179-1183.

Boyle, G. J. (1990a). A review of the factor structure of the Sixteen Personality Factor Questionnaire and the Clinical Analysis Questionnaire. Psychological Test Bulletin, $\underline{3}, 40-45$.

Boyle, G. J. (1990b). Stanford-Binet IV Intelligence Scale: Is its structure supported by LISREL congeneric factor analyses? Personality and Individual Differences, 11, $1175-1181$.

Boyle, G. J. (1991a). Experimental psychology does require a multivariate perspective. Contemporary Psychology, 36, 350-351.

Boyle, G. J. (1991b). Interset relationships between the Eight State Questionnaire and the Menstrual Distress Questionnaire. Personality and Individual Differences, 12, 703711.

Boyle, G. J. (1991c). Item analysis of the subscales in the Eight State Questionnaire (8SQ): Exploratory and confirmatory factor analyses. Multivariate Experimental Clinical Research, 10, 37-65.

Boyle, G. J. (1999). Pavlovian Temperament Survey (PTS): Australian normative data. In J. Strelau, A. Angleitner, \& B. H. Newberry. The Pavlovian Temperament Survey (PTS): An international handbook (pp. 78-84). Seattle, WA: Hogrefe \& Huber. 
Boyle, G. J. (1992). Multidimensional Mood State Inventory (MMSI). Unpublished, Department of Psychology, University of Queensland.

Boyle, G. J. (1993a). Intelligence and personality measurement within the Cattellian psychometric model. In G.L. Van Heck, P. Bonaiuto, I. J. Deary, \& W. Nowack (Eds.), Personality psychology in Europe, Vol. 4 (pp. 183-201). Tilburg: Tilburg University Press.

Boyle, G. J. (1993b). Evaluation of the exploratory factor analysis programs provided in SPSSX and SPSS/PC+. Multivariate Experimental Clinical Research, 10, 129-135.

Boyle, G. J. (1995). Measurement of intelligence and personality within the Cattellian psychometric model. Multivariate Experimental Clinical Research, 11, 47-59.

Boyle, G. J. (2006a). Five Factor Model of personality structure. In D. Westen, L. Burton, \& R. Kowalski (Eds.), Psychology: Australian and New Zealand edition (p. 443). Milton, Queensland: Wiley.

Boyle, G. J. (2006b). Scientific analysis of personality and individual differences. D.Sc.Thesis. St. Lucia: University of Queensland.

Boyle, G. J., \& Cattell, R. B. (1984). Proof of situational sensitivity of mood states and dynamic traits--ergs and sentiments--to disturbing stimuli. Personality and Individual Differences, 5, 541-548.

Boyle, G. J., \& Cattell, R. B. (1987). A first survey of the similarity of personality and motivation prediction of 'in situ' and experimentally controlled learning, by structured learning theory. Australian Psychologist, 22, 189-196.

Boyle, G. J., \& Comer, P. G. (1990). Personality characteristics of direct-service personnel in community residential units. Australia and New Zealand Journal of Developmental Disabilities, 16, 125-131. 
Boyle, G. J., \& Houndoulesi, V. (1993). Utility of the School Motivation Analysis Test in predicting second language acquisition. British Journal of Educational Psychology, $\underline{63}, 500-512$.

Boyle, G. J., \& Katz, I. (1991). Multidimensional scaling of the Eight State Questionnaire and the Differential Emotions Scale. Personality and Individual Differences, 12, 565-574.

Boyle, G. J., Ortet, G., \& Ibáñez, M. I. (2001). Evaluación de la personalidad y la inteligencia: Una perspectiva cattelliana (Evaluation of personality and intelligence: A Cattellian perspective). Universitas Tarraconensis Revista de Psicología, 23, 7392.

Boyle, G. J., Richards, L. M., \& Baglioni, Jr., A. J. (1993). Children's Motivation Analysis Test (CMAT): An experimental manipulation of curiosity and boredom. Personality and Individual Differences, 15, 637-643.

Boyle, G. J., \& Robertson, J. M. (1989). Anomaly in equation for calculating 16PF secondorder factor QIII. Personality and Individual Differences, 10, 1007-1008.

Boyle, G. J., \& Saklofske, D H. (2004). (Eds.), Editors’ Introduction. Sage benchmarks in psychology: The psychology of individual differences. London: Sage.

Boyle, G. J., \& Smári, J. (1997). De fem stora och personlighetspsykologins matningsproblem (The big five and measurement problems in personality psychology). Nordisk Psykologi (Nordic Psychology), 49, 12-21.

Boyle, G. J., \& Smári, J. (1998). Statiska femfaktorpersonlighets-modeller-Svar till Engvik (Static five-factor models of personality: A reply to Engvik). Nordisk Psykologi (Nordic Psychology), 50, 216-222.

Boyle, G. J., \& Smári, J. (2002). Vers une simplification du modèle cattellien de la personnalité. Bulletin de Psychologie, 55, 635-643. 
Boyle, G. J., Stankov, L., \& Cattell, R. B. (1995). Measurement and statistical models in the study of personality and intelligence. In D. H. Saklofske \& M. Zeidner (Eds.), International handbook of personality and intelligence (pp. 417-446). New York: Plenum.

Boyle, G. J., \& Stanley, G. V. (1986). Application of factor analysis in psychological research: Improvement of simple structure by computer-assisted graphic oblique transformation. Multivariate Experimental Clinical Research, 8, 175-182.

Boyle, G. J., Stanley, G. V., \& Start, K. B. (1985). Canonical/redundancy analyses of the Sixteen Personality Factor Questionnaire, the Motivation Analysis Test, and the Eight State Questionnaire. Multivariate Experimental Clinical Research, 7, 113122.

Boyle, G. J., \& Start, K. B. (1988). A first delineation of higher-order factors in the Children's Motivation Analysis Test (CMAT). Psychologische Beiträge, 30, 556567.

Boyle, G. J., \& Start, K. B. (1989a). Comparison of higher-order motivational factors across sexes using the Children's Motivation Analysis Test. Personality and Individual Differences, 10, 483-487.

Boyle, G. J., \& Start, K. B. (1989b). Sex differences in the prediction of academic achievement using the Children's Motivation Analysis Test. British Journal of Educational Psychology, 59, 245-252.

Boyle, G. J., Start, K. B., \& Hall, E. J. (1988). Comparison of Australian and American normative data for the School Motivation Analysis Test. Psychological Test Bulletin, 1, 24-27. 
Boyle, G. J., Start, K. B., \& Hall, E. J. (1989a). Dimensions of adolescent motivation as measured by higher-order factors in the School Motivation Analysis Test. $\underline{\text { Journal }}$ of School Psychology, 27, 27-33.

Boyle, G. J., Start, K. B., \& Hall, E. J. (1989b). Prediction of academic achievement using the School Motivation Analysis Test. British Journal of Educational Psychology, $\underline{59}, 92-99$.

Cattell, H. E. P. (1993)."The structure of phenotypic personality traits": Comment. American Psychologist, 48, 1302-1303.

Cattell, H. E.P. (2004). The Sixteen Personality Factor (16PF) questionnaire. In M. J. Hilsenroth, \& D. L. Segal. (Eds.), Comprehensive handbook of psychological assessment (Vol. 2): Personality assessment. (pp. 39-49). Hoboken, NJ: Wiley.

Cattell, H. E. P. (2001). The Sixteen Personality Factor (16PF) Questionnaire. In W. I. Dorfman, \& M. Hersen (Eds), Understanding psychological assessment (pp. 187-215). Dordrecht, Netherlands: Kluwer Academic.

Cattell, H. E. P, \& Schuerger, J. M. (2003). Essentials of 16PF assessment. Hoboken, NJ: Wiley.

Cattell, R. B. (1973). Personality and mood by questionnaire. San Francisco, CA: JosseyBass.

Cattell, R. B. (1978). The scientific use of factor analysis in behavioral and life sciences. New York: Plenum.

Cattell, R. B. (1979). Personality and learning theory, Vol. 1: The structure of personality in its environment. New York: Springer.

Cattell, R. B. (1980a). Personality and learning theory, Vol. 2.: A systems theory of maturation and structured learning. New York: Springer. 
Cattell, R. B. (1980b). Personality theory derived from quantitative experiment (Vol. 1). In H. I. Kaplan, A. M. Freeman, \& B. J. Sadock (Eds.), Comprehensive textbook of psychiatry (3rd ed.). Baltimore, MD: Williams \& Wilkin.

Cattell, R. B. (1981). Where next in human motivation research? Some possible crucial experiments. In R. Lynn (Ed.), Dimensions of personality: Papers in honor of H.J. Eysenck. Oxford, UK: Pergamon.

Cattell, R. B. (1982a). The development of Cattellian structured systems theory of personality: The VIDAS model. Zeitschrift fur Differentielle und Diagnostische Psychologie, 3, 7-25.

Cattell, R. B. (1982b). The psychometry of objective motivation measurement: A response to the critique of Cooper and Kline. British Journal of Educational Psychology, 52, 234-241.

Cattell, R. B. (1983). Structured personality-learning theory: A wholistic multivariate research approach. New York: Praeger.

Cattell, R. B. (1984). Personality as a scientifically based concept. In J. Kuper \& M. Kuper (Eds.), The social science encyclopedia (pp. 10-37). London: Routledge \& Kegan Paul.

Cattell, R. B. (1985). Human motivation and the dynamic calculus. New York: Praeger.

Cattell, R. B. (1986a). Dodging the third error source: Psychological interpretation and use of given scores. In In R. B. Cattell, \& R. C. Johnson (Eds.), Functional psychological testing: Principles and instruments (pp. 496-543). New York: Brunner/Mazel.

Cattell, R. B. (1986b). General principles across the media of assessment. In R. B. Cattell, \& R. C. Johnson (Eds.), Functional psychological testing: Principles and instruments (pp. 15-32). New York:Brunner/Mazel. 
Cattell, R. B. (1986c). Selecting, administering, scoring, recording, and using tests in assessment. In R. B. Cattell, \& R.C. Johnson (Eds.), Functional psychological testing: Principles and instruments (pp. 105-126). New York: Brunner/Mazel.

Cattell, R. B. (1986d). Structured tests and functional diagnoses. In R. B. Cattell, \& R. C. Johnson (Eds.), Functional psychological testing: Principles and instruments (pp. 314). New York: Brunner/Mazel.

Cattell, R. B. (1986e).The actual trait, state, and situation structures important in functional testing. In R. B. Cattell, \& R. C. Johnson (Eds.), Functional psychological testing: Principles and instruments (pp.33-53). New York: Brunner/Mazel.

Cattell, R. B. (1986f).The psychometric properties of tests: Consistency, validity, and efficiency. In R. B. Cattell, \& R. C. Johnson (Eds.), Functional psychological testing: Principles and instruments (pp. 54-78). New York: Brunner/Mazel.

Cattell, R. B. (1986g). The 16PF personality structure and Dr. Eysenck. Journal of Social Behavior and Personality, 1, 153-160.

Cattell, R. B. (1987a). Intelligence: Its structure, growth and action. Amsterdam: North Holland.

Cattell, R. B. (1987b). Psychotherapy by structured learning theory. New York: Springer.

Cattell, R. B. (1988a). Handling prediction from psychological states and roles by modulation theory. In S. G. Cole, R. G. Demaree, \& W. Curtis (Eds.). Applications of interactionist psychology: Essays in honor of Saul B. Sells. Hillsdale, NJ.:Erlbaum.

Cattell, R. B. (1988b). Psychological theory and scientific method. In J. R. Nesselroade \& R. B. Cattell (Eds.), Handbook of multivariate experimental psychology (2nd ed.). New York: Plenum. 
Cattell, R. B. (1988c). The data box: Its ordering of total resources in terms of possible relational systems. In J. R. Nesselroade \& R. B. Cattell (Eds.), multivariate experimental psychology ( $2^{\text {nd }}$ ed. $)$. New York: Plenum.

Cattell, R. B. (1988d). The meaning and strategic use of factor analysis. In J. R. Nesselroade \& R. B. Cattell (Eds.), $\underline{\text { Handbook of multivariate experimental }}$ psychology ( $2^{\text {nd }}$ ed. $)$. New York: Plenum.

Cattell, R. B. (1988e).The principles of experimental design and analysis in relation to theory building. In J. R. Nesselroade \& R. B. Cattell (Eds.), Handbook of multivariate experimental psychology ( $2^{\text {nd }}$ ed.). New York: Plenum.

Cattell, R. B. (1990a). Advances in Cattellian personality theory. In L. A. Pervin (Ed.), Handbook of personality: Theory and action (pp. 101-110). New York: Guilford.

Cattell, R. B. (1990b). The birth of the Society of Multivariate Experimental Psychology. Journal of the History of the Behavioral Sciences, 26, 48-57.

Cattell, R. B. (1990c). The experimental testing of the Vidas systems theory. Journal of Mathematical Psychology, 34, 109-115.

Cattell, R. B. (1992). Human motivation objectively, experimentally analysed. British Journal of Medical Psychology, 65, 237-243.

Cattell, R. B. (1994). Constancy of global, second-order personality factors over a twenty-year-plus period. Psychological Reports, 75, 3-9.

Cattell, R. B. (1995). The fallacy of five factors in the personality sphere. The Psychologist, May, 207-208.

Cattell, R. B. (1996). What is structured learning theory? British Journal of Educational Psychology, 66, 411-413.

Cattell, R. B., \& Birkett, H. (1980). The known personality factors found aligned between first order T-data and second order Q-data factors, with new evidence on the 
inhibitory control, independence and regression traits. Personality and Individual Differences, 1, 229-238.

Cattell, R. B., Boyle, G. J., \& Chant, D. (2002). The enriched behavioral prediction equation and its impact on structured learning and the dynamic calculus. Psychological Review, 109, 202-205.

Cattell, R. B., \& Cattell, H. E. P. (1995). Personality structure and the new fifth edition of the 16PF. Educational and Psychological Measurement, 6, 926-937.

Cattell, R. B., \& Cattell, A. K. S. (1977). Measuring intelligence with the culture fair tests. Champaign, IL: Institute for Personality and Ability Testing.

Cattell, R. B., \& Child, D. (1975). Motivation and dynamic structure. London: Holt, Rinehart \& Winston.

Cattell, R. B., Eber, H. W., \& Tatsuoka, M. M. (1970). Handbook for the Sixteen Personality Factor Questionnaire. Champaign, IL: Institute for Personality and Ability Testing.

Cattell, R. B., \& Horn, J. L. (1982). Whimsy and misunderstanding of Gf-Gc theory: A comment on Guilford. Psychological Bulletin, 91, 621-633.

Cattell, R. B., \& Johnson, R. C. (Eds.). (1986). Functional psychological testing: Principles and instruments. New York: Brunner/Mazel.

Cattell, R. B., \& Kameoka, V. A. (1985). Psychological states measured in the Clinical Analysis Questionnaire (CAQ). Multivariate Experimental Clinical Research, 7, 6987.

Cattell, R. B., \& Kline, P. (1977). The scientific analysis of personality and motivation. New York: Academic. 
Cattell, R. B., \& Krug, S. E. (1986). The number of factors in the 16PF: A review of the evidence with special emphasis on methodological problems. Educational and Psychological Measurement, 46, 509-522.

Cattell, R. B., \& Nesselroade, J. R. (1988). (Eds.), Handbook of multivariate experimental psychology ( $2^{\text {nd }}$ ed. $)$. New York: Plenum.

Cattell, R. B., \& Schuerger, J. M. (1978). Personality theory in action: Handbook for the Objective-Analytic (O-A) Test Kit. Champaign, IL: Institute for Personality and Ability Testing.

Cattell, R. B., \& Vogelmann, S. (1977). A comprehensive trial for the scree and KG criteria for determining the number of factors. Multivariate Behavioral Research, 12, 289325.

Cattell, R. B., \& Warburton, F. W. (1967). Objective personality and motivation tests: A theoretical introduction and practical compendium. Champaign, IL: University of Illinois Press.

Child, D. (1990). The essentials of factor analysis ( $2^{\text {nd }}$ ed.). London: Cassell.

Cronbach, L. J. (1957). The two disciplines of scientific psychology. American Psychologist, 12, 671-684.

Curran, J. P., \& Cattell, R. B. (1976). Manual for the Eight State Questionnaire. Champaign, IL: Institute for Personality and Ability Testing.

Eysenck, H. J. (1984). Cattell and the theory of personality. Multivariate Behavioral Research, 19, 323-336.

Eysenck, H. J. (1997). Personality and experimental psychology: The unification of psychology and the possibility of a paradigm. Journal of Personality and Social Psychology, 73, 1224-1237. 
Eysenck, H. J., \& Eysenck, M. W. (1985). Personality and individual differences: A natural science approach. New York: Plenum.

Fernandez, E., \& Boyle, G. J. (1996). Meta-analytic procedure and interpretation of treatment outcome and test validity for the practitioner psychologist. In M. Smith \& V. Sutherland (Eds.), International review of professional issues in selection and assessment, Vol. 2 (pp. 109-125). New York: Wiley.

Fisher, C. D., \& Boyle, G. J. (1997). Personality and employee selection: Credibility regained. Asia Pacific Journal of Human Resources, 35, 26-40.

Gorsuch, R. L. (1983). Factor analysis ( $2^{\text {nd }}$ ed.). Hillsdale, NJ: Erlbaum.

Grossarth-Maticek, R., Eysenck, H. J., \& Boyle, G J. (1995). Method of test administration as a factor in test validity: The use of a personality questionnaire in the prediction of cancer and coronary heart disease. Behaviour Research and Therapy, 33, 705-710.

Haggbloom, S. J., Warnick, R., Warnick, J. E., Jones, V. K., Yarbrough, G. L., Russell, T. M., Borecky, C. M., McGahhey, R., Powell III, J. L., Beavers, J., \& Monte, E. (2002). The 100 most eminent psychologists of the $20^{\text {th }}$ century. Review of General Psychology, 6, 139-152.

Hakstian, A. R., \& Cattell, R. B. (1982). Manual for the Comprehensive Ability Battery. Champaign, IL: Institute for Personality and Ability Testing.

Kline, P. (1979). Psychometrics and psychology. London: Academic.

Kline, P. (1980). The psychometric model. In A. J. Chapman \& D. M. Jones (Eds.), Models of man. Leicester, UK: The British Psychological Society.

Krug, S. E. (1980). Clinical Analysis Questionnaire Manual. Champaign, IL: Institute for Personality and Ability Testing.

Krug, S. E. (1981). Interpreting 16PF profile patterns. Champaign, IL, Institute for Personality and Ability Testing. 
Krug, S. E., \& Johns, E. F. (1986). A large scale cross-validation of second-order personality structure defined by the 16PF. Psychological Reports, 59, 683-693.

McArdle, J. J. (1984). On the madness in his method: R. B. Cattell’s contributions to Structural Equation Modelling. Multivariate Behavioral Research, 19, 245-267.

McArdle, J. J., \& Cattell, R. B. (1994). Structural equation models of factorial invariance in parallel proportional profiles and oblique confactor problems. Multivariate Behavioral Research, 29, 63-113.

Nesselroade, J. R., \& Cattell, R. B. (1988). (Eds.), Handbook of multivariate experimental psychology (2nd ed.). New York: Plenum.

Roberts, B. W., Walton, K. E., Viechtbauer, W. (2006a). Patterns of mean-level change in personality traits across the life course: A meta-analysis of longitudinal studies. Psychological Bulletin, 132, 1-25.

Roberts, B. W., Walton, K. E., Viechtbauer, W. (2006b). Personality traits change in adulthood: Reply to Costa and McCrae (2006). Psychological Bulletin, 132, 29-32.

Schuerger, J. M. (1986). Personality assessment by objective tests. In R. B. Cattell \& R. C. Johnson (Eds.), Functional psychological testing: Principles and instruments (pp. 260-287). New York: Brunner/Mazel.

Smith, B. D. (1988). Personality: Multivariate systems theory and research. In J. R. Nesselroade \& R. B. Cattell (Eds.), $\underline{\text { Handbook of multivariate experimental }}$ psychology $\left(2^{\text {nd }}\right.$ ed.). New York: Plenum.

Stankov, L., Boyle, G. J., \& Cattell, R. B. (1995). Models and paradigms in personality and intelligence research. In D. H. Saklofske \& M. Zeidner (Eds.), International handbook of personality and intelligence (Ch. 2, pp. 15-43). New York: Plenum. 
Sweney, A. R., Anton, \& Cattell, R. B. (1986). Evaluating motivation structure, conflict, and adjustment. In R. B. Cattell \& R. C. Johnson (Eds.), Functional psychological testing: Principles and instruments (pp. 288-315). New York: Brunner/Mazel. 
Table 1

Reduced Set of 30 Broad Factors -- Boyle Psychometric Model

Normal Personality: (five factors)

Extraversion, Neuroticism, Tough Poise, Independence, Control

Abnormal Personality: (six factors)

Depressive Schizophrenia, Psychopathic Dominance, Psychotic Inadequacy, Paranoid Depression, Helpless Depression, Anxious Depression

Motivation: (adult--seven factors)

Home Orientation, Pugnacity, Narcism (narcissism), Career Orientation, Fear, Self-sentiment, Superego

Normal Mood States: (five factors)

Extraversion State, Anxiety-Neuroticism State, Anger-Hostility State, Curiosity State, Arousal-Fatigue State

Abnormal Mood States: (two factors)

Paranoid State, Psychopathic Dominance State

Cognitive Abilities: (five factors)

Memory Capacity, Perceptual Speed, Retrieval Capacity, Visualisation Capacity, Auditory Organisation 